\title{
Nghiên cứu thực nghiệm một số tính chất của bê tông rỗng sử dụng vật liệu nhiễm mặn
}

Nguyễn Tuấn Trung ${ }^{1}$, Nguyễn Văn Đồng ${ }^{1}$

1 Trường Đại học Xây dựng Hà Nội, 55 Giải Phóng, Hai Bà Trưng, Hà Nội

\section{TỬ KHOÁ}

Bê tông rỗng

Độ rỗng

Xỉ lò cao nghiền mịn (GBFS)

Silica fume (SF)

Cát biển

Nước biển
TÓM TÁT

Bê tông rỗng có hệ thống lỗ rỗng hở thông nhau, chúng giúp nước dễ dàng thấm qua khi có mưa, đây là loại bê tông được ứng dụng nhiều trong các đô thị nhằm giảm hiện tượng ngập úng cục bộ. Với đặc điểm rỗng chúng cũng có thể được ứng dụng làm các công trình ven biển, hải đảo như đường bao, kết cấu giảm sóng. Tuy nhiên, ở các vùng đó thường rất khó khăn về nguyên liệu chế tạo như cát, nước. Trong bài báo này chúng tôi xin giới thiệu bê tông rỗng được chế tạo từ đá dăm có kích thước hạt từ 5 đến 10 mm, hỗn hợp chất kết dính gồm $60 \%$ xi măng $+10 \%$ silica fume $(\mathrm{SF})+30 \%$ xỉ lò cao nghiền mịn (GBFS), cát biển, nước biển Hải Phòng kết hợp với phụ gia siêu dẻo, với 3 độ rỗng thiết kế là $15 \%$; 20 $\%$ và $25 \%$, sử dụng cát biển với các hàm lượng $4 \% ; 7 \%$ và $10 \%$. Các kết quả đã đánh giá được ảnh hưởng của độ rỗng, hàm lượng cát tới một số tính chất của bê tông rỗng như độ rỗng, khối lượng thể tích, cường độ, hệ số thoát nước.

\begin{abstract}
Pervious concrete has a system of open pores, they help water easily seep through when it rains, this is a type of concrete widely used in urban areas to reduce local flooding. With their hollow characteristics, they can also be applied to coastal and island structures such as contours, wave-reducing structures. However, in those same areas, it is often very difficult in terms of manufacturing materials such as sand and water. In this paper, we would like to introduce hollow concrete made from crushed stone with particle size (5 - 10) mm, a binder mixture consisting of $60 \%$ cement $+10 \%$ silica fume (SF) $+30 \%$ Ground Blast Furnace Slag (GBFS), sea sand, Hai Phong sea water combined with superplasticizers, with 3 design porosity of $15 \% ; 20 \%$ and $25 \%$, using sea sand with concentrations of $4 \%$; $7 \%$ and $10 \%$. The results have evaluated the influence of porosity, sand content on some properties of hollow concrete such as porosity, volumetric weight, strength, drainage coefficient.
\end{abstract}

\section{Giới thiệu}

Theo Viện bê tông Mỹ (ACI) [3], bê tông rỗng (BTR) là loại bê tông không có độ sụt, dùng cấp phối hạt gián đoạn gồm có xi măng poóc lăng, cốt liệu lớn, một lượng nhỏ hoặc không cốt liệu nhỏ, nước và phụ gia. Sau khi rắn chắc từ hỗn hợp vật liệu trên, bê tông sẽ có hệ thống lỗ rỗng thông nhau cho phép nước chảy qua dễ dàng. Độ rỗng của bê tông có thể thay đổi từ $15 \%$ đến $35 \%$, cường độ nén từ 2,8 MPa đến $28 \mathrm{MPa}$. Tốc độ thoát nước của BTR thay đổi tùy theo kích thước cốt liệu và khối lượng thể tích của hỗn hợp bê tông và thường vào khoảng từ 81 đến 730 lít/phút/m² (1,35 đến 12,17 mm/s).

Hiện nay trên thế giới bê tông rỗng chủ yếu được ứng dụng làm các kết cấu trong công trình giao thông như mặt đường, vỉa hè, bãi đỗ xe, .... [4-6] sẽ giảm úng ngập trong đô thị vào mùa mưa gây ảnh hưởng lớn đến đời sống sinh hoạt và hoạt động lao động sản xuất của người dân, hệ thống tiêu thoát nước và xử lý nước thải đô thị sẽ được giảm tải nên chi phí đầu tư cho các công trình hạ tầng đô thị, xử lý nước thải sẽ giảm mạnh. Khi xây dựng đường bằng bê tông rỗng gần như không cần đầu tư thêm hệ thống ống cống tiêu thoát nước hai bên đường bởi tự bản thân nó đã có khả năng tiêu, thoát nước. Vì vậy, BTR có ý nghĩa rất lớn đóng góp lớn cho sự phát triển của ngành thoát nước đô thị và xử lý nước thải trong đô thị.

Gần đây, năm 2011 hãng BASF của CHLB Đức đã đưa ra một sản phẩm bê tông cấu trúc rỗng Elastocoast áp dụng cho các kè ở các khu vực ven biển và ổn định bờ sông. Bê tông rỗng này trên cơ sở chất kết dính hữu cơ polyurethane có chức năng tiêu/giảm năng lượng sóng và thực tế đã khẳng định hiệu quả này trong quá trình sử dụng.

Việt Nam là quốc gia có tiềm năng lớn về biển, hải đảo khi có hơn 1 triệu $\mathrm{km}^{2}$ diện tích mặt biển, bờ biển dài hơn 3000 km trải dài từ Bắc tới Nam, hàng ngàn hòn đảo lớn nhỏ. Vùng ven biển là nơi có nguồn tài nguyên phong phú, là động lực phát triển kinh tế của đất nước, nhưng cũng là nơi chịu nhiều tác động của thiên tai như bão, lũ, xói lở, nhiễm mặn,.... Đây là khu vực có vị trí đặc biệt quan trọng đối với phát triển kinh tế-xã hội, phòng chống thiên tai, ứng phó với BĐKH, đảm bảo quốc phòng, an ninh. Vùng ven biển là sản phẩm của các quá trình địa chất, thủy văn, hải văn, khí tượng, sinh học và hoạt động nhân sinh, rất nhạy cảm với BĐKH và thiên tai và hoạt động nhân sinh, đặc 
biệt là đô thị ven biển, các khu du lịch, các khu công nghiệp ven biển. Đây lại là vùng bị tổn thương rất cao do BĐKH.

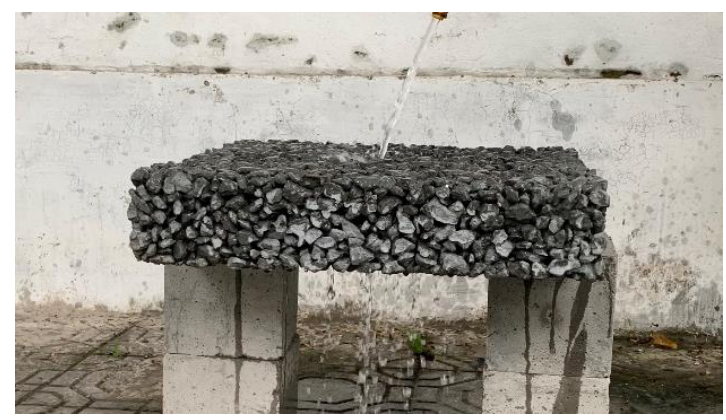

Hình 1. Mẫu bê tông rỗng

Theo tính chất xâm thực và mức độ tác động lên kết cấu bê tông \& bê tông cốt thép (BTCT) có thể phân môi trường biển Việt Nam thành 4 vùng: Vùng hoàn toàn ngập trong nước biển, Vùng nước lên xuống (bao gồm cả phần sóng đánh), Vùng khí quyển trên và ven biển, Vùng đất nước ngầm bờ biển. Các đặc điểm nổi bật của môi trường biển là nhiệt độ, độ ẩm không khí cao, thời gian ẩm ướt kéo dài, nồng độ muối trong nước biển, không khí trên biển và ven biển cao, các công trình xây dựng ven biển còn chịu ảnh hưởng của nước lên xuống và sóng đánh. Khi sóng biển truyền vào vùng ven bờ, nó bị biến dạng và khúc xạ do giảm độ sâu và tăng ma sát đáy. Các yếu tố của sóng biến đổi. Diễn biến của sóng ở ven bờ phụ thuộc vào đường bờ và tính chất biến đổi của địa hình đáy. Nếu sóng đi vào vùng bờ dốc đứng và sâu, thì sóng hầu như không biến đổi các yếu tố của nó cho đến tận sát bờ. Khi đạt tới bờ nó bị phản xạ trở lại. Kết hợp sóng tới và sóng phản xạ sẽ tạo thành sóng đứng với bụng sóng ở gần bờ, biên độ dao động nâng lên và hạ xuống của mặt sóng bằng khoảng hai lần độ cao sóng tới.

Khi sử dụng bê tông đặc chắc làm các cấu kiện trong công trình ven bờ, khi có tác động của sóng gặp các bề mặt bê tông thì sẽ bị phản ngược lại gây xói mòn và hư hỏng cấu trúc, chẳng hạn như bong tróc các hạt cốt liệu. Tuy vậy, khi tạo được cấu trúc rỗng thông nhau thì sóng biển sẽ được phân tán vào các lỗ rỗng với các hướng khác nhau, đồng thời tạo các cấu trúc rỗng lớn trong kết cấu ngầm, do đó có chức năng giảm tác động của sóng và giữ ổn định cho các cụm kết cầu ngầm.

Tuy có cấu trúc rỗng nhưng lượng xi măng sử dụng để chế tạo loại bê tông này cũng khá lớn, khoảng $275 \div 415 \mathrm{~kg} / \mathrm{m}^{3}$ [7]. Do đó, để giảm lượng xi măng sử dụng nhiều nghiên cứu đã sử dụng thêm các phụ gia khoáng để thay thế một phần xi măng như silica fume, tro bay, xỉ lò cao, ...[8-10].

\section{Nguyên vật liệu sử dụng}

Trong nghiên cứu sử dụng các nguyên vật liệu gồm: Xi măng PC40 Bút Sơn có các tính chất đạt theo tiêu chuẩn TCVN $2682: 2009$ [1], khối lượng riêng $3,1 \mathrm{~g} / \mathrm{cm}^{3}$; Xỉ lò cao nghiền mịn, có khối lượng riêng $2,94 \mathrm{~g} / \mathrm{cm}^{3}$; Silica fume sử dụng của hãng Elkem có khối lượng riêng $2,20 \mathrm{~g} / \mathrm{cm}^{3}$; thành phần hóa của xi măng, xỉ lò cao, silica fume được thể hiện trong Bảng 1. Phụ gia siêu dẻo sử dụng là ACE388 của hãng Basf, có dung trọng là $1,08 \mathrm{~g} / \mathrm{cm}^{3}$; nước sử dụng thỏa mãn theo TCVN 4506 : 2012 [2] nước dùng cho vữa và bê tông.

Bảng 1.

Thành phần hóa của vật liệu sử dụng.

\begin{tabular}{|c|c|c|c|c|c|c|c|c|}
\hline \multirow{2}{*}{$\begin{array}{c}\text { Vật } \\
\text { liệu }\end{array}$} & \multicolumn{7}{|c|}{ Thành phần hóa, \% } \\
\cline { 2 - 9 } & $\mathrm{SiO}_{2}$ & $\mathrm{Al}_{2} \mathbf{O}_{3}$ & $\mathbf{F e}_{2} \mathbf{O}_{3}$ & $\mathbf{C a O}$ & $\mathbf{M g O}$ & $\mathbf{K}_{2} \mathbf{O}$ & $\mathbf{N a}_{2} \mathbf{O}$ & $\mathbf{M K N}$ \\
\hline $\begin{array}{c}\mathrm{Xi} \\
\text { măng }\end{array}$ & 22,58 & 5,72 & 3,45 & 61,23 & 0,65 & & & 1,71 \\
\hline $\begin{array}{c}\text { Xỉ lò } \\
\text { cao }\end{array}$ & 34,52 & 12,38 & 0,66 & 41,54 & 7,25 & 0,24 & 0,43 & 0,96 \\
\hline $\begin{array}{c}\text { Silica } \\
\text { fume }\end{array}$ & 93,45 & 0,92 & 0,52 & 1,57 & & & & 4,20 \\
\hline
\end{tabular}

Cốt liệu sử dụng là đá dăm với cỡ hạt $(5$ - 10) mm, tính chất của cốt liệu được thể hiện trong Bảng 2.

Bảng 2.

Tính chất cơ lý của cốt liệu lớn.

\begin{tabular}{|c|l|c|c|}
\hline TT & \multicolumn{1}{|c|}{ Chỉ tiêu } & Đơn vị & Kết quả \\
\hline 1 & Khối lượng riêng & $\mathrm{g} / \mathrm{cm}^{3}$ & 2,72 \\
\hline 2 & Khối lượng thể tích chọc chặt & $\mathrm{kg} / \mathrm{m}^{3}$ & 1620 \\
\hline 3 & Độ rỗng chọc chặt & $\%$ & 41,0 \\
\hline 4 & Hàm lượng bùn, bụi, sét & $\%$ & 0,12 \\
\hline 5 & Cường độ nén dập trong xi lanh & $\%$ & 5,0 \\
\hline
\end{tabular}

Cốt liệu nhỏ được sử dụng để đúc mẫu thí nghiệm là cát biển Đồ Sơn - Hải Phòng. Cát được sấy khô, sau đó đóng thành túi và được bảo quản khô. Các đặc tính kỹ thuật của cát được thí nghiệm theo tiêu chuẩn TCVN 7572 : 2006. Các tính chất kỹ thuật cát biển theo Bảng 3.

Bảng 3.

Kết quả thí nghiệm cát biển Hải Phòng.

\begin{tabular}{|c|l|c|c|}
\hline STT & \multicolumn{1}{|c|}{ Chỉ tiêu kiểm tra } & Đơn vị & Kết quả \\
\hline 1 & Khối lượng riêng & $\mathrm{g} / \mathrm{cm}^{3}$ & 2,673 \\
\hline 2 & Khối lượng thể tích xốp & $\mathrm{g} / \mathrm{cm}^{3}$ & 2,591 \\
\hline \multirow{2}{*}{3} & Modul độ lớn & - & 2,10 \\
\cline { 2 - 4 } & Lượng hạt $<0,14 \mathrm{~mm}$ & $\%$ & 1,18 \\
\cline { 2 - 4 } & Lượng hạt $>5 \mathrm{~mm}$ & $\%$ & 0,02 \\
\hline 4 & Hàm lượng bụi bùn sét & $\%$ & 0,86 \\
\hline 5 & Hàm lượng ion clo $(\mathrm{Cl})$ & $\%$ & 0,007 \\
\hline
\end{tabular}

Trong nghiên cứu tác giả sử dụng nước biển được lấy từ vùng biển Đồ Sơn - Hải Phòng dùng làm nước để trộn bê tông. Trong nước biển chứa chủ yếu các ion $\mathrm{Cl}^{-}, \mathrm{Na}^{+}, \mathrm{SO}_{4}{ }^{2-}, \mathrm{K}^{+}, \mathrm{Mg}^{2+}$ với ion $\mathrm{Cl}^{-}, \mathrm{Na}^{+}$ 
chiếm tỷ lệ lớn (88 \% khối lượng các muối) tồn tại ở dạng muối $\mathrm{NaCl}$ hòa tan. Thông số của nước biển được thể hiện trong Bảng 4.

\section{Bảng 4.}

Thông số của nước biển của một số bờ biển khảo sát.

\begin{tabular}{|c|c|c|c|c|c|c|c|}
\hline Loại nước & Độ $\mathbf{p H}$ & $\begin{array}{c}\mathrm{Cl}^{-} \\
(\mathrm{g} / \mathrm{l})\end{array}$ & $\begin{array}{c}\mathrm{Ca}^{2+} \\
(\mathrm{g} / \mathbf{l})\end{array}$ & $\begin{array}{c}\mathbf{M g}^{2+} \\
(\mathrm{g} / \mathrm{l})\end{array}$ & $\begin{array}{c}\mathbf{S O}_{4}{ }^{2-} \\
(\mathrm{g} / \mathrm{l})\end{array}$ & $\begin{array}{c}\mathbf{K}^{+} \\
(\mathrm{g} / \mathrm{l})\end{array}$ & $\begin{array}{c}\mathbf{N a}^{+} \\
(\mathrm{g} / \mathrm{l})\end{array}$ \\
\hline $\begin{array}{l}\text { Nước biển } \\
\text { Hải Phòng }\end{array}$ & 7,5 & 16,4 & 0,34 & 1,08 & 2,1 & 0,12 & 9,17 \\
\hline
\end{tabular}

\section{Phương pháp thí nghiệm}

\subsection{Xác định độ rỗng}

Để xác định độ rỗng của BTR được tính bằng hàm lượng khí theo phương pháp phân tích trọng lượng theo ASTM C138, ta tiến hành cân trong nước các mẫu trụ có đường kính $10 \mathrm{~cm}$ và chiều cao $20 \mathrm{~cm}$. Trình tự tiến hành như sau: Đầu tiên xác định thể tích của mẫu $\mathrm{V}_{0}$ rồi ngâm ngập mẫu trong nước trong thời gian 24 giờ. Giỏ lưới được treo vào cân điện tử và thả chìm trong thùng chứa đầy nước, đợi cho mực nước ổn định và dùng bút mực đánh dấu mực nước. Ấn nút cân điện tử về mức 0,00 . Sau đó đưa mẫu vào giỏ từ từ, để cho mẫu ổn định thoát hết khí trong mẫu rồi múc bớt nước ra về mực đã đánh dấu. Sau đó ghi lại khối lượng mẫu ở trạng thái cân trong nước. Lấy mẫu ra để ráo nước rồi đưa vào tủ sấy ở $105^{\circ} \mathrm{C}$ trong 24 h. Lấy mẫu ra để nguội và cân khối lượng mẫu khô ngoài không khí.

Độ rỗng của bê tông rỗng thoát nước được xác định theo công thức:

$$
r=\left(1-\frac{M_{2}-M_{1}}{\rho_{n} \cdot V_{0}}\right) \cdot 100 \%
$$

Trong đó:

$$
\begin{aligned}
& \mathrm{M}_{1} \text { : khối lượng mẫu trong nước, } \mathrm{g} \\
& \mathrm{M}_{2} \text { : khối lượng mẫu khô, } \mathrm{g} \\
& \mathrm{V}_{0} \text { : thể tích mẫu, } \mathrm{cm}^{3} \\
& \rho_{\mathrm{n}} \text { : khối lượng riêng của nước, } \mathrm{g} / \mathrm{cm}^{3}
\end{aligned}
$$

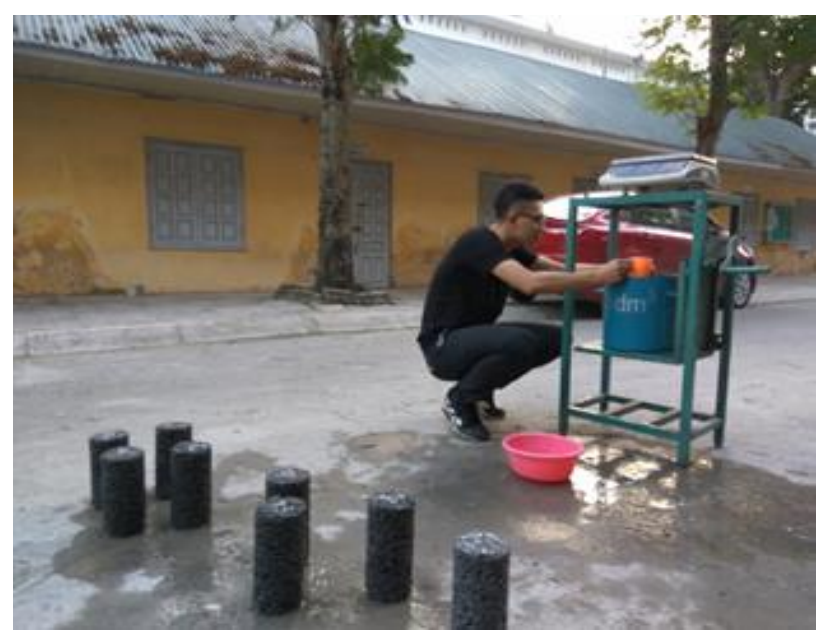

Hình 2. Thí nghiệm xác định độ rỗng của BTR.

\subsection{Xác định hệ số thoát nước}

Để xác định hệ số thoát nước của BTR, ta tiến hành thí nghiệm theo phương pháp dòng chảy thay đổi dựa trên định luật Darcy. Trình tự thí nghiệm như sau:

- Chế tạo BTR thành mẫu trụ, kích thước D $\times$ H $=100 \times 200$ mm.

- Tháo khuôn sau khi chế tạo 24 giờ, dưỡng hộ tự nhiên (có thể thí nghiệm ngay sau khi tháo khuôn hoặc ở các tuổi bất kỳ), vớt mẫu để ráo nước, dùng giấy nilong bọc kín bề mặt xung quanh mẫu.

- Đưa mẫu đã bọc vào trong ống của dụng cụ thử, dùng hỗn hợp vữa chèn kín vành mẫu đảm bảo không có khe hở ở giữa bề mặt mẫu và bề mặt trong ống và chắc chắn rằng nước sẽ chảy xuyên qua tiết diện dọc theo mẫu.

- Đổ nước vào ống đến vạch chiều cao $\mathrm{H}_{1}$ duy trì 10 phút cho nước điền đầy vào lỗ rỗng mẫu và mực nước ổn định nếu mực nước hạ thấp thì bổ sung vào cho đến $\mathrm{H}_{1}$.

- Mở van thật nhanh và đồng thời bấm đồng hồ. Khi mực nước hạ đến $\mathrm{H}_{2}$ thì dừng đồng hồ, ghi lại thời gian mực nước hạ từ $\mathrm{H}_{1}$ xuống $\mathrm{H}_{2}$.
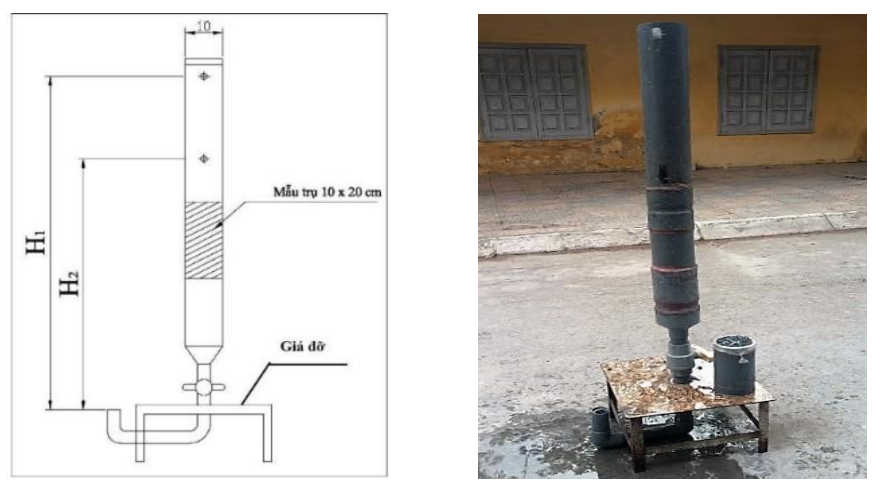

Hình 3.1 Sơ đồ và dụng cụ xác định hệ số thoát nước.

Đo các thông số hình học như sơ đồ và tính toán hệ số thoát nước theo phương pháp cột nước thay đổi, $\mathrm{K}_{\mathrm{t}}(\mathrm{mm} / \mathrm{s})$, theo công thức:

$$
\mathrm{K}_{\mathrm{t}}=\frac{\text { A.L }}{\mathrm{F} . \mathrm{t}} \cdot \ln \frac{\mathrm{H}_{1}}{\mathrm{H}_{2}} \quad(\mathrm{~mm} / \mathrm{s})
$$

Trong đó:

A - Tiết diện ngang của ống đo áp, $\mathrm{mm}^{2}$;

$\mathrm{L}$ - Chiều cao (chiều dài đường thoát nước) của mẫu, mm;

F - Tiết diện ngang của mẫu, $\mathrm{mm}^{2}$

$\mathrm{H}_{1}$ - Chiều cao cột nước ban đầu trong ống đo áp, mm;

$\mathrm{H}_{2}$ - Chiều cao cột nước trong ống đo áp sau thời gian thoát nước $\mathrm{t}, \mathrm{mm}$;

$\mathrm{t}$ - Thời gian thoát nước ứng với cột nước từ $\mathrm{H}_{1}$ hạ xuống đến $\mathrm{H}_{2}, \mathrm{~s}$.

\subsection{Xác định cường độ nén}

Cường độ nén của bê tông rỗng được xác định theo tiêu chuẩn ASTM C39, với mẫu hình trụ kích thước $100 \times 200$ mm. 


\subsection{Cấp phối thí nghiệm}

Trong nghiên cứu này tác giả sử dụng cốt liệu lớn cỡ hạt (5 - 10) mm, chất kết dính sử dụng hỗn hợp gồm xi măng, SF và GBFS, cát biển với các hàm lượng $4 \%$; 7 và $10 \%$, do cát có kích thước hạt mịn nên chúng được tính vào thành phần của hỗn hợp chất kết dính bọc xung quanh hạt cốt liệu lớn. Sau khi tính toán ta được cấp phối được thể hiện trong Bảng 5 .

\section{Bảng 5.}

Cấp phối bê tông rỗng.

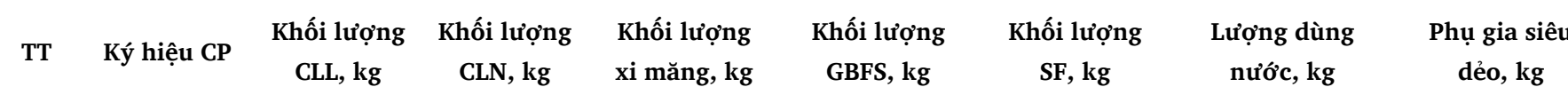

\begin{tabular}{|c|c|c|c|c|c|c|c|c|}
\hline 1 & S0/r15 & 1574 & 0 & 297 & 84,8 & 42,4 & 93,3 & 1,7 \\
\hline 2 & $\mathrm{~S} 0 / \mathrm{r} 20$ & 1574 & 0 & 237 & 67,8 & 33,9 & 74,6 & 1,4 \\
\hline 3 & $\mathrm{~S} 0 / \mathrm{r} 25$ & 1574 & 0 & 178 & 50,8 & 25,4 & 55,8 & 1,0 \\
\hline 4 & S4/r15 & 1574 & 63 & 269 & 76,8 & 38,4 & 84,4 & 1,5 \\
\hline 5 & $\mathrm{~S} 4 / \mathrm{r} 20$ & 1574 & 63 & 209 & 59,8 & 29,9 & 65,7 & 1,2 \\
\hline 6 & $\mathrm{~S} 4 / \mathrm{r} 25$ & 1574 & 63 & 150 & 42,7 & 21,4 & 47 & 0,9 \\
\hline 7 & S7/r15 & 1574 & 110 & 248 & 70,8 & 35,4 & 77,8 & 1,4 \\
\hline 8 & $\mathrm{~S} 7 / \mathrm{r} 20$ & 1574 & 110 & 188 & 53,7 & 26,9 & 59,1 & 1,1 \\
\hline 9 & S7/r25 & 1574 & 110 & 129 & 36,7 & 18,4 & 40,4 & 0,7 \\
\hline 10 & $\mathrm{~S} 10 / \mathrm{r} 15$ & 1574 & 157 & 227 & 64,7 & 32,4 & 71,2 & 1,3 \\
\hline 11 & $\mathrm{~S} 10 / \mathrm{r} 20$ & 1574 & 157 & 167 & 47,7 & 23,9 & 52,5 & 1,0 \\
\hline 12 & $\mathrm{~S} 10 / \mathrm{r} 25$ & 1574 & 157 & 107 & 30,7 & 15,4 & 33,8 & 0,6 \\
\hline
\end{tabular}

Ghi chú: Ký hiệu mẫu SO/r15 được hiểu là cốt liệu nhỏ sử dụng 0 \%; độ rỗng thiết kế là $15 \%$.

\section{Kết quả thí nghiệm}

BTR được đúc các mẫu trụ $100 \times 200$ mm để tiến hành xác định các tính chất: độ rỗng thực tế, khối lượng thể tích, hệ số thoát nước và cường độ nén theo các tuổi 3; 7; 28; 60 và 120 ngày. Kết quả thí nghiệm được thể hiện trong Bảng 6.

Bảng 6.

Kết quả thí nghiệm các tính chất của BTR.

\begin{tabular}{|c|c|c|c|c|c|c|c|c|c|}
\hline \multirow{2}{*}{ TT } & \multirow{2}{*}{ Ký hiệu CP } & \multirow{2}{*}{$\begin{array}{c}\text { Độ rỗng } \\
\text { thực tế, \% }\end{array}$} & \multirow{2}{*}{$\begin{array}{c}\text { Khối lượng thể } \\
\text { tích, kg/m³ }\end{array}$} & \multirow{2}{*}{$\begin{array}{l}\text { Hệ số thoát } \\
\text { nước, mm/s }\end{array}$} & \multicolumn{5}{|c|}{ Cường độ nén theo tuổi, MPa } \\
\hline & & & & & 3 ngày & 7 ngày & 28 ngày & 60 ngày & 120 ngày \\
\hline 1 & S0/r15 & 16,2 & 1924 & 3,7 & 20,1 & 24,1 & 26,3 & 24,5 & 24,1 \\
\hline 2 & $\mathrm{~S} 0 / \mathrm{r} 20$ & 21,4 & 1864 & 6,2 & 16,7 & 20,2 & 22,2 & 20,6 & 20,3 \\
\hline 3 & S0/r25 & 26,3 & 1786 & 9,9 & 13,4 & 16,2 & 17,8 & 15,4 & 15,3 \\
\hline 4 & $\mathrm{~S} 4 / \mathrm{r} 15$ & 16,8 & 1943 & 4,2 & 18,8 & 22,4 & 24,5 & 22,8 & 22,4 \\
\hline 5 & $\mathrm{~S} 4 / \mathrm{r} 20$ & 21,9 & 1883 & 6,8 & 16,1 & 18,8 & 20,4 & 18,9 & 18,7 \\
\hline 6 & $\mathrm{~S} 4 / \mathrm{r} 25$ & 26,9 & 1813 & 10,2 & 12,4 & 12,8 & 14,4 & 13,3 & 13,1 \\
\hline 7 & S7/r15 & 17,0 & 1955 & 4,6 & 17,2 & 20,4 & 22,3 & 20,6 & 20,4 \\
\hline 8 & $\mathrm{~S} 7 / \mathrm{r} 20$ & 22,4 & 1897 & 7,1 & 14,4 & 16,8 & 18 & 16,8 & 16,5 \\
\hline 9 & $\mathrm{~S} 7 / \mathrm{r} 25$ & 27,1 & 1818 & 10,4 & 10,4 & 11,2 & 12,2 & 11,3 & 11,1 \\
\hline 10 & $\mathrm{~S} 10 / \mathrm{r} 15$ & 17,3 & 1962 & 4,9 & 15,2 & 17,6 & 19,4 & 17,9 & 17,7 \\
\hline 11 & $\mathrm{~S} 10 / \mathrm{r} 20$ & 22,4 & 1903 & 7,6 & 14,4 & 16 & 17,4 & 16,1 & 16,2 \\
\hline 12 & $\mathrm{~S} 10 / \mathrm{r} 25$ & 27,9 & 1826 & 10,7 & 10,1 & 10,6 & 11,6 & 10,7 & 10,2 \\
\hline
\end{tabular}




\section{1. Độ rỗng thực tế}

Độ rỗng thực tế của BTR được xác định bằng phương pháp cân trong nước theo tiêu chuẩn ASTM C138. Ở tất cả các cấp phối độ rỗng thực tế đều cao hơn độ rỗng thiết kế từ 1,2 \% đến 2,9 \%, ở độ rỗng thiết kế càng lớn thì độ chênh càng cao. Khi tăng lượng dùng cốt liệu nhỏ độ sai lệch cũng tăng dần, do các hạt cốt liệu nhỏ chèn vào điểm tiếp xúc giữa các hạt cốt liệu lớn làm tăng độ rỗng, mức độ lèn chặt của các hạt vào nhau giảm đi đáng kể các hạt cốt liệu không tiếp xúc trực tiếp với nhau.

\subsection{Khối lượng thể tích}

Mối quan hệ giữa khối lượng thể tích với độ rỗng thực tế được thể hiện trong Hình 3. Ảnh hưởng của độ rỗng tới khối lượng thể tích của BTR. Từ kết quả ta thấy: khối lượng thể tích của BTR trong khoảng $1786 \mathrm{~kg} / \mathrm{m}^{3}$ đến $1962 \mathrm{~kg} / \mathrm{m}^{3}$ và tỷ lệ nghịch với độ rỗng thiết kế, ở độ rỗng thiết kế $20 \%$ khối lượng thể tích đạt khoảng $1864 \mathrm{~kg} / \mathrm{m}^{3}$ bằng khoảng $70 \%$ so với bê tông thường (bê tông thường có khối lượng thể tích khoảng $2500 \mathrm{~kg} / \mathrm{m}^{3}$ ). Khi tăng dần hàm lượng cốt liệu nhỏ ở tất cả các độ rỗng thiết kế, khối lượng thể tích tăng dần do cốt liệu nhỏ làm tăng trọng lượng riêng của lớp vữa bọc xung quanh bề mặt cốt liệu lớn.

\subsection{Hệ số thoát nước}

Hệ số thoát nước được xác định theo định luật Darcy, kết quả xác định ảnh hưởng của độ rỗng tới hệ số thoát nước được thể hiện trong Hình 4. Theo kết quả ta thây:

- Hệ số thoát nước phụ thuộc chủ yếu vào độ rỗng, độ rỗng tăng làm tăng nhanh hệ số thoát nước, mức độ tăng càng lớn khi độ rỗng càng cao. Khi độ rỗng thiết kế tăng từ $15 \%$ lên $20 \%$ thì tốc độ tăng hệ số thoát nước trung bình đạt $0,5 \mathrm{~mm} \cdot \mathrm{s}^{-1} / 1 \%$ độ rỗng, nhưng khi tăng từ độ rỗng $20 \%$ lên $25 \%$ tốc độ tăng hệ số thoát nước trung bình đạt 0,9 $\mathrm{mm} \cdot \mathrm{s}^{-1} / 1 \%$ độ rỗng, khi độ rỗng lớn làm giảm nhanh ma sát giữa dòng chảy và thành vách lỗ rỗng hở làm tăng nhanh tốc độ dòng chảy của nước.

- Khi cùng độ rỗng thiết kế, tăng hàm lượng cốt liệu nhỏ thì hệ số thoát nước tăng nhẹ, ở độ rỗng thiết kế $15 \%$ khi không sử dụng CLN có hệ số thấm $3,7 \mathrm{~mm} / \mathrm{s}$ còn khi sử dụng thêm 7 \% CLN thì hệ số thấm tăng

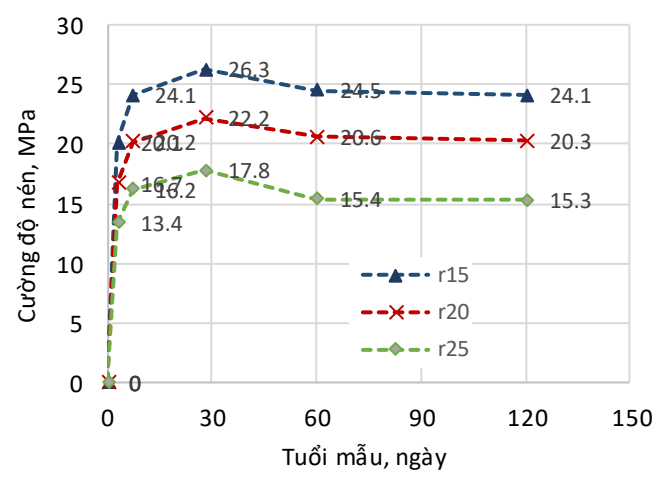

Hình 5. Cường độ nén bê tông rỗng, khi hàm lượng cát 0 \%. lên 4,6 mm/s (tăng khoảng 24 \%). Khi có mặt CLN, chúng sẽ chèn vào giữa điểm tiếp xúc của các hạt CLL, các hạt CLL bị đẩy nhau ra làm tăng nhẹ độ rỗng và kích thước lỗ rỗng.

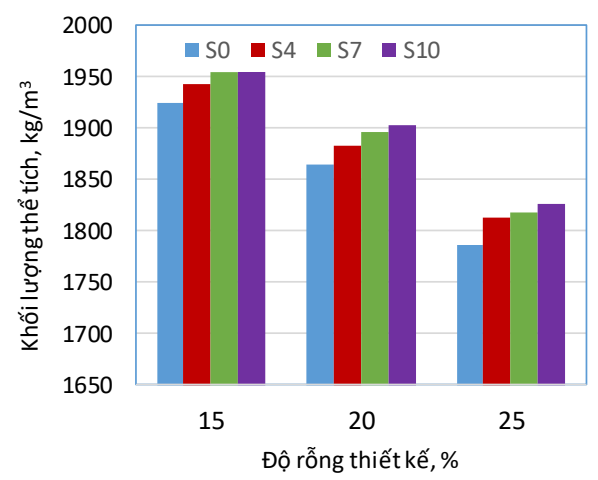

Hình 3. Ảnh hưởng của độ rỗng tới khối lượng thể tích của BTR.

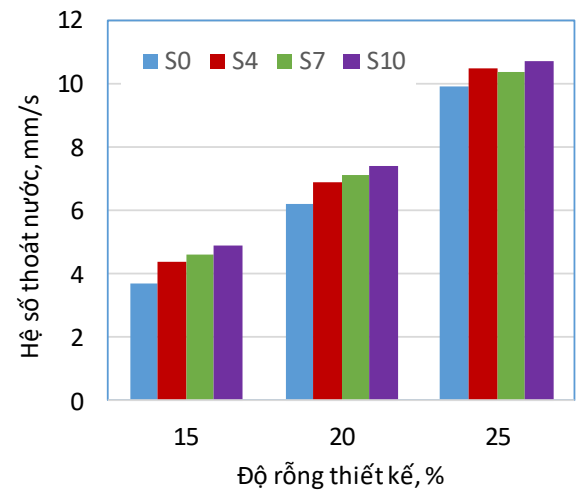

Hình 4. Ảnh hưởng của độ rỗng tới hệ số thoát nước của BTR.

\subsection{Cường độ nén}

Cường độ nén của BTRTN được xác định trên mẫu trụ, kích thước $100 \times 200 \mathrm{~mm}$ theo tiêu chuẩn ASTM C39. Để đánh giá cả tốc độ phát triển cường độ theo thời gian, đề tài tiến hành xác định cường độ nén ở các tuổi 3 ngày; 7 ngày; 28 ngày; 60 ngày và 120 ngày. Kết quả thí nghiệm được thể hiện trong Hình 5 đến Hình 8.

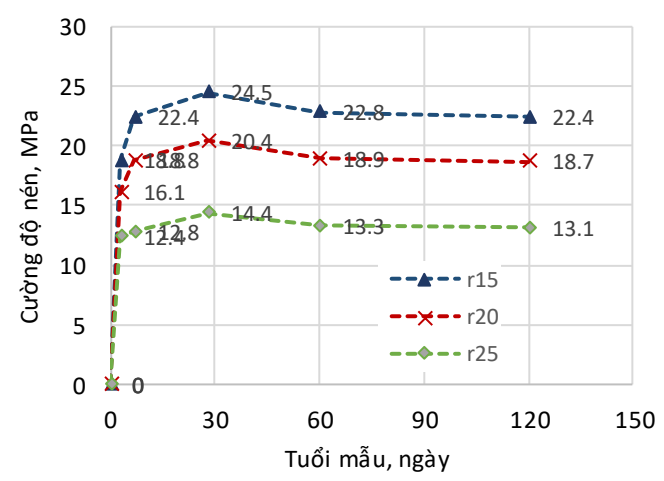

Hình 6. Cường độ nén bê tông rỗng, khi hàm lượng cát 4 \%. 


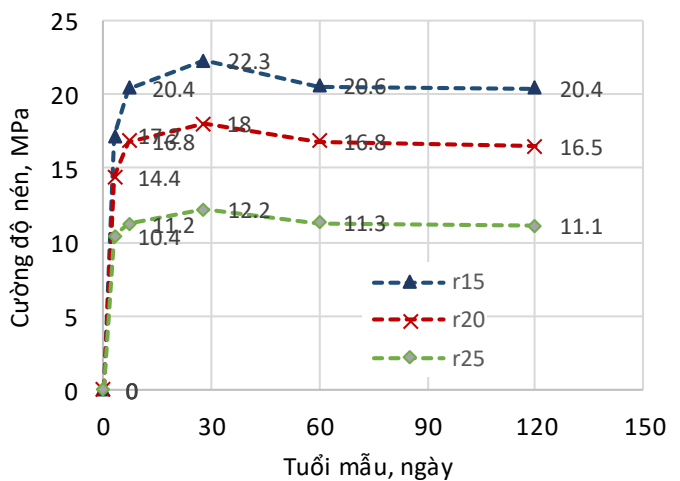

Hình 7. Cường độ nén bê tông rỗng, khi hàm lượng cát 7 \%.

Theo kết quả ta thấy: cường độ nén tỷ lệ nghịch với độ rỗng thực tế. Khi tăng độ rỗng thiết kế nhưng khung cốt liệu vẫn được giữ nguyên (lượng dùng đá không đổi), chủ yếu điều chỉnh lượng dùng hồ CKD (lượng hồ CKD giảm), làm giảm lượng hồ gắn kết giữa các hạt cốt liệu (hay giảm diện tích vùng tiếp xúc giữa các hạt), từ đó làm giảm liên kết giữa các hạt và giảm cường độ của BTR. Mức độ giảm càng nhành khi độ rỗng càng lớn. Khi tăng độ rỗng từ $15 \%$ lên $20 \%$ tốc độ giảm trung bình là $0,75 \mathrm{MPa} / 1 \%$ độ rỗng, nhưng khi độ rỗng tăng từ $20 \%$ lên $25 \%$ tốc độ giảm trung bình là $1,16 \mathrm{MPa} / 1 \%$ độ rỗng.

- Cường độ ở tuổi sớm ngày khá cao, cường độ ở tuổi 3 ngày đạt khoảng 80 \% cường độ ở tuổi 28 ngày, ở tuổi 7 ngày đạt khoảng $91 \%$ cường độ ở tuổi 28 ngày. Tốc độ phát triển cường độ ở tuổi sớm ngày nhanh hơn khá nhiều so với bê tông thường, do bê tông có cấu trúc rỗng hở lớn, khả năng tiếp xúc với nước ở giai đoạn đầu thuận lợi, khả năng thoát nước tự do nhanh, đồng thời trong nước biển có ion $\mathrm{Cl}^{-}$ chúng giúp đẩy nhanh quá trình rắn chắc của bê tông ở tuổi sớm ngày. Tuy nhiên, ở các tuối dài ngày (60 ngày và 120 ngày) cường độ bê tông lại giảm dần. Sự suy giảm cường độ này là do muối $\mathrm{SO}_{4}{ }^{2-}$ và muối $\mathrm{Cl}^{-}$ và có trong cát biển và nước biển phản ứng với $\mathrm{Ca}(\mathrm{OH})_{2}$ tạo ra các muối $\mathrm{CaSO}_{4}, \mathrm{CaCl}_{2}$. Muối tạo thành tác dụng tiếp với $\mathrm{C}_{3} \mathrm{~A}$ tạo thành khoáng ettringite chứa nhiều nước kết tinh tăng thể tích lên khoảng 2,5 lần gây phá hoại cấu trúc đá xi măng, tốc độ giảm nhanh trong khoảng 30 đến 60 ngày, sau đó chậm lại và dần ổn định.

- Khi cùng độ rỗng thiết kế, tăng hàm lượng cốt liệu nhỏ từ $0 \%$ lên 10 \% (giảm lượng dùng xi măng, phụ gia) thì cường độ có giảm dần. Cốt liệu nhỏ sử dụng được tính vào lớp hồ bọc xung quanh hạt cốt liệu lớn nên giảm đáng kể lượng dùng xi măng và phụ gia nhưng lại làm giảm cường độ hỗn hợp $\mathrm{CKD}$ và giảm dần cường độ bê tông. Tại độ rỗng thiết kế là $20 \%$, khi hàm lượng cốt liệu nhỏ $0 \%$ thì cường độ nén ở tuổi 28 ngày đạt 21,7 MPa khi tăng hàm lượng cốt liệu nhỏ đến 10 \% thì cường độ giảm còn 17,4 MPa (tức giảm khoảng 20 \%).

\section{Kết luận}

Trong bài báo này tác giả sử dụng hỗn hợp phụ gia khoáng silica fume với xỉ lò cao nghiền mịn kết hợp với nước biển và cát biển Hải

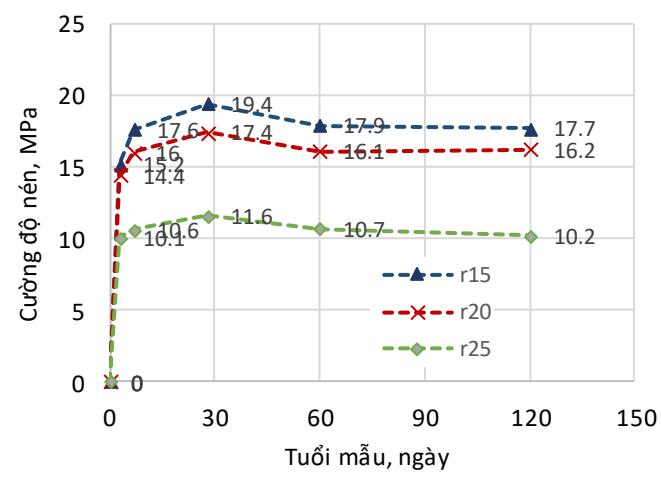

Hình 8. Cường độ nén bê tông rỗng, khi hàm lượng cát 10 \%.

Phòng để chế tạo bê tông rỗng, nghiên cứu xác định một số tính chất của bê tông rỗng và rút ra một số kết luận như sau:

- Độ rỗng thực tế cao hơn độ rỗng thiết kế từ 1,2 đến 2,3 \%, khi độ rỗng thiết kế càng lớn thì độ sai lệch càng cao.

- Khối lượng thể tích của bê tông rỗng phụ thuộc chủ yếu vào độ rỗng và bằng khoảng 70 \% so với bê tông thường.

- Hệ số thoát nước của bê tông rỗng tỷ lệ thuận với độ rỗng của bê tông, tuy nhiên tốc độ tăng nhanh khi độ rỗng thiết kế lớn hơn $20 \%$.

- Cường độ nén của bê tông rỗng phát triển rất nhanh ở tuổi sớm ngày, ở tuổi 3 ngày đã đạt khoảng $80 \%$. Tuy nhiên sau 28 ngày cường độ có xu hướng giảm dần do tác động của một số loại muối có trong nước biển và cát biển.

Với các kết quả trên hoàn toàn có thể chế tạo được bê tông rỗng đạt mác M20, độ rỗng thiết kế $20 \%$ để đảm bảo khả năng thoát nước. Đây là tiền đề để ứng dụng loại bê tông này làm các kết cấu cho các công trình ven biển, hải đảo.

\section{Lời cảm ơn}

Bài báo được thực hiện với sự hỗ trợ về tài chính của đề tài CT.2020.04.XDA.06. Các tác giả chân thành cảm ơn Bộ Giáo dục và Đào Tạo, Trường Đại học Xây dựng đã hỗ trợ và tạo mọi điều kiện thuận lợi để thực hiện đề tài này.

\section{Tài liệu tham khảo}

[1]. TCVN 2682 : 2009. Xi măng pooc lăng - Yêu cầu kỹ thuật.

[2]. TCVN 4506 : 2012. Nước cho bê tông và vữa - Yêu cầu kỹ thuật.

[3]. ACI 211.3R-02. Guide for Selecting Proportions for No-Slump Concrete, Reported by ACI Committee 211.

[4]. Kayhanian; M, Anderson; D, Harvey; JT, Jones; D, Muhunthan B. Permeability measurement and scan imaging to assess clogging of pervious concrete pavements in parking lots. Journal of Environmental Management, 2012;95:114-23.

[5]. Saeid Hesami, Saeed Ahmadi, Mahdi Nematzadeh. Effects of rice husk ash and fiber on mechanical properties of pervious concrete pavement. Construction and Building Materials, 2014 (Faculty of Civil Engineering, Babol Noshirvani University of Technology, 47148-71167 Babol, Iran). 
[6]. Jing Yang, Guoliang Jiang. Experimental study on properties of pervious concrete pavement materials. Cement and Concrete Research 33 (2003) 381-386, 2003.

[7]. R.Schaefer. Mix design development for pervious concrete in cold weather climates. National Concrete Pavement Technology Centre, Final Report, 2006.

[8]. Yuwadee Zaetang, Ampol Wongsa, Vanchai Sata, Prinya Chindaprasirt. Use of coal ash as geopolymer binder and coarse aggregate in pervious concrete. Construction and Building Materials, 2015;96:289-95.

[9]. Tawatchai Tho-in, Vanchai Sata, Prinya Chindaprasirt, Chai Jaturapitakkul. Pervious high-calcium fly ash geopolymer concrete. Construction and Building Materials, 30 (2012) 366-371.

[10]. D. Sun, F. Yu, L. Li. Effect of chemical composition and structure of asphalt binders on self-healing, Construction and Building Materials, 2017;133:495-501. 